
Pathophysiology of Haemostasis and Thrombosis

\title{
Disease Transmission by Blood Products: Past, Present and Future
}

\author{
William G. Murphy \\ Irish Blood Transfusion Service, Dublin, Ireland
}

\section{Key Words}

Blood products $\cdot$ Safety $\cdot$ Infection $\cdot$ Non-linear systems

\begin{abstract}
Transfusion of blood and blood products has been associated with transmission of infectious agents. However, it is probable that blood products are currently very safe and that pooled virus-inactivated products from remunerated donors are now safer than untreated single voluntary donor components. Although the transmission events of the past and the present are reasonably well understood, reliance on a linear approach to predict safety in the future is open to criticism. Indeed, it was not possible to predict the extent or consequences of the AIDS epidemic or of hepatitis $C$ transmission. Moreover, although variant Creutzfeldt-J akob disease (vCJ D) may not be transmitted to any large extent by transfusion of manufactured blood products, this will be due more to good fortune than good judgement - this agent could have escaped the screening, testing and eradication methods on which current confidence in blood product safety depends. Similarly, the emergence of a highly resistant non-enveloped virus, or even of another previously unrecognised disease-causing agent, could result in new threats from transfusion of blood components and products. The ecology of blood transfusion is
\end{abstract}

exquisitely sensitive to variations in starting conditions, a situation typical of a chaotic rather than a linear system. Seemingly trivial events, often apparently unrelated to blood transfusion, have had enormous consequences in this field. Whatever the events that introduced simian immunodeficiency virus to humans or scrapie to cattle, they were a long way from those involved in the manufacture of blood products. In such a setting, reliance on methods that deal effectively with known threats (such as encapsulated viruses and bacteria) without adequate investigation and management of the intrinsic sensitivity to unpredictable events, leaves open the possibility of further infections emerging in the future. It is this reality that will ultimately result in the eradication of the transfusion of donor-derived blood and blood products in the developed world. In addition, all infections with a long disease-free incubation period in the host that can be transmitted in blood will eventually be over-expressed in groups that are exposed to blood either recreationally or professionally. As in the past, this could have occurred before testing or decontamination processes have been developed for emerging pathogens. Failure to be able to rely on completely risk-free donors, in both the voluntary and non-voluntary sides of the blood industry, continues to offer the potential for the transmission of infectious diseases in the future.

Copyright @2002 S. Karger AG, Basel

\begin{tabular}{ll}
\hline KARGER & ( 2002 S. Karger AG, Basel \\
Fax +41613061234 & 1424-8832/02/0327-0001\$18.50/0 \\
$\begin{array}{l}\text { E-Mail karger@karger.ch } \\
\text { www.karger.com }\end{array}$ & $\begin{array}{l}\text { Accessible online at: } \\
\text { www.karger.com/journals/pht }\end{array}$
\end{tabular}

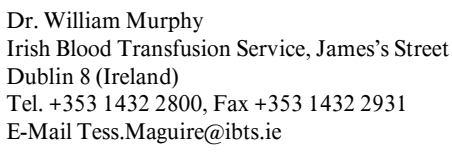




\section{Introduction}

Evidence-based medicine uses data from the past and present to make predictions with a greater or lesser degree of confidence about the future. In the case of blood and blood product safety, the value of such predictions requires careful assessment and considerable scepticism. Although considerable effort has gone into making blood products as safe as possible, their future safety depends on many more variables than are immediately obvious. The screening techniques that have been developed so far can only work against diseases that have already been identified. Inactivation techniques are similarly limited, and are not universally effective. Further, as yet unrecognisable risks may exist, making it impossible to make assertions of the safety of the blood supply based on what we currently know. Science does not predict the future, and may be "nothing more than a sharper set of questions to guide us through the fog' [1] - we cannot make assertions or predictions of future events, and, if we persist in doing so we may impede appropriate planning based on realistic uncertainty.

\section{Past Infections in Blood Products}

The ecology of blood collection, storage and transfusion generates distinct patterns of disease. The use of fresh unstored blood and vein-to-vein transfusion resulted in syphilis being a major concern in the early years of blood transfusion. Storage of blood in the cold in turn led to the emergence of psychrophilic bacteria as a lethal complication in the 1940s and 1950s. In the 1970s the widespread acceptance of $22^{\circ} \mathrm{C}$ as the optimum temperature for platelet storage was accompanied by the rise of serious gram-positive and gram-negative infections from transfusion of these components.

\section{Current Infections}

Malaria, parvovirus B19, and cytomegalovirus are still major infectious problems from blood transfusion, although the extent is not well documented globally. These infections are not routinely screened for in all donations. While there remains a small risk of undetected window period infections from HIV and hepatitis $\mathrm{C}$ in developed countries, these agents can be expected to be removed from blood derivatives during manufacture. This has led to the current situation where pooled virus inactivated derivatives are considered safer than non-pooled singledonor non-virus inactivated products, at least in so far as such agents are concerned.

However, current inactivation techniques applied to blood derivatives do not remove all infectious agents. TT virus, while it may not be associated with transmissible morbidity, nevertheless serves as a marker for viral resilience to current inactivation techniques. A recent study showed that this virus could be transmitted via the albumin used in the manufacture of recombinant VIIIc and IX [2]. Similarly, parvovirus B19 can escape eradication in the manufacturing of albumin, indicating that the potential exists for viral transmission from future blood products [3].

\section{Future Infections}

\section{Non-Linear Science and Blood Transfusion}

While formal proof is lacking, the blood transfusion ecosystem shows some characteristics of the chaotic behaviour found in systems composed of complex interdependent components. For example, a seemingly trivial or remote event in the system can result in catastrophic consequences over considerable ranges of space and time.

\section{$H I V$}

An example of a minor, apparently unrelated change with disastrous consequences was the appearance of HIV in blood transfusion in the 1980s. It is possible that the transmission of simian immunodeficiency virus to humans may have been occurring in West Africa for a long time previously, but it was the beginning of forest clearance in the area that allowed the infection to spread out of the forest to the general population. Thus an apparently unrelated commercial desire for hardwoods may have led to thousands of deaths from transfusion and millions of deaths from AIDS, and will probably lead to collapse of national economies.

\section{Yersinia Infection}

A less dramatic but nonetheless intriguing example of a minor event having a major impact could have been the emergence of $Y$. enterocolitica as a hazard of transfusion in 1978. This organism, which carries a $70 \%$ mortality as a septic complication of blood transfusion, was not previously associated with blood transfusion, and it is unlikely that it would have been missed as a diagnosis. There have been well over 100 cases since, emerging in blood transfusion recipients in several countries around the 
same time. However, there seems to have been no significant change in epidemiology in the general population. The outbreak followed the introduction of plasma reduction during the late 1970s, and all cases were from plasmareduced blood units, although the relationship is not clear. Normally, pathogenic Yersinia are killed as blood cools from between 32 and $10^{\circ} \mathrm{C}$ [4]. Plasma reduction shortens the time for blood cooling, and this may have affected the susceptibility of the organism to complement killing.

However, it is also very possible that plasma reduction had an unexpected benefit, preventing thousands of deaths from fluid overload.

Classic linear approaches will not provide definitive answers to the appearance of Yersinia in blood transfusion. Similarly, such approaches will not explain and did not predict a surge in maternal deaths from haemorrhage between 1988 and 1990 (table 1) [5]. This may have been linked to a rise in the use of red cell concentrates around that time for transfusion in these women rather than whole blood. While this will always remain speculative, it underlines the susceptibility of the blood transfusion world to unexpected events arising from seemingly unrelated triggering factors.

If the blood transfusion system does follow the rules of chaos theory and is therefore a complex non linear system, then it poses a major problem for manipulating the risk of future transmissible infections. Although we have safer blood products now than ever before, the safety precautions can only reliably ward off known threats. Any new, previously uncharacterised infections could emerge unchallenged because current procedures do not test for them or may not inactivate them. For this reason, the use of blood products will remain inherently unsafe. If, for example, variant CJD is not being transmitted by blood products, this is due to luck rather than safety procedures - this agent could have escaped the screening, testing and eradication methods currently in use.

\section{Strategies for Risk Reduction}

The future to combating transfusible diseases in a system that, while not utterly unpredictable, is nonetheless subject to the laws of chaos rather than linear science is not totally bleak. Risk reduction in a non-linear system is not a simple affair, but recognition of the chaotic nature of the problem will be of some use, not least if it avoids spurious reliance on assertions based on an invalid linear approach. 'Not only in research, but in the everyday world of politics and economics, we would all be better off if
Table 1. Maternal deaths from haemorrhage in the UK, 1985-1993, showing an as yet unexplained rise in deaths between 1988-1990

\begin{tabular}{llll}
\hline $\begin{array}{l}\text { Number of maternal deaths } \\
\text { from haemorrhage }\end{array}$ & 10 & 22 & 12 \\
Time period & $85-87$ & $81-90$ & $91-93$ \\
\hline
\end{tabular}

more people realised that simple non-linear systems do not necessarily possess simple dynamical properties' [6].

Approaches to risk reduction in complex systems might include removal of feedback lops where possible, which should have the effect of reducing the rate of generation of unpredictable effects. This approach provides a rational basis for the removal of paid donors, and for the removal of transfused donors, as sources of blood and plasma. While such donors may not provide a current source of infection, they do provide an important feedback loop that increases the variability of the system.

\section{Paid Donations as a Feedback Loop}

Infections (other than bacterial contamination) transmissible by blood products have several more or less essential characteristics: they are spread by blood contact such as needle-sharing in IV drug abusers; they do not result in clinical disease until some time after infectivity in the host is established, and a test for infectivity in donors is not available until the existence of the disease is established. This set of preconditions has resulted in the fact that any new infection transmitted by blood transfusion will be over-represented in professional blood and plasma donors by the time screening is put in place and subject to exponential spread within this group.

This was true for HIV, hepatitis B and hepatitis C [7]. It is also true for HCV NAT screening - data from Germany indicate that hepatitis $\mathrm{C}$ positivity by NAT testing is eight times more likely from paid rather than nonremunerated donors ( 17 positive donors out of 2.3 million donations in paid donors versus 11 out of 12.7 million non-remunerated donors - relative risk 8.394 (95\% CI 3.9-17.9) $\mathrm{p}<0.0001)$ [8]. It is evident that paid donors are withholding information on risk activity at a much higher rate than non-remunerated donors.

While previously transfused individuals represent a lesser risk, they do provide a feedback loop that amplifies any infection that is dormant, unscreened for, and not removed during processing and manufacture.

Ultimately this complex and largely unpredictable behaviour in the transfusion ecosystem will only be con-

Disease Transmission by Blood Products 
trolled by abandoning the use of blood and blood products. While this in itself would give rise to unpredictable effects elsewhere in the universe of healthcare, it is extremely important that unfounded reassurances on blood safety do not obstruct proper planning for future safety.

\section{Conclusion}

Current confidence in the safety of blood and blood products is misguided. Our methods of screening and inactivation of viruses are simply linear solutions which will not work on sufficiently large scales of time and space for a non-linear complex system such as blood transfusion. Hence it would be inappropriate to take comfort from the successful control of HCV, HIV, and other currently recognised infections. We have not yet developed the tools in the blood product industry or in public health to predict and then cope with new risks as they arise. The system is extremely sensitive to unpredictable events, leaving it highly vulnerable to future threats. Further disastrous epidemics could well arise in the future.

It is this unpredictability that will eventually lead to the eradication of the transfusion of donor-derived blood and blood products.

\section{References}

1 May R: Risk and Uncertainty. Nature 2001; 411:891.

2 Azzi A, Santis R, Morfini M, Zakrzewska K, Musso R, Santagostino E, Castarnan G: TT virus contaminates first-generation recombinant factor VII concentrates. Blood 2001;98: 2571-2573.

3 Saldanha J, Minor P: Detection of human parvovirus B19 DNA in plasma pools and blood products derived from these pools: Implications for efficacy and consistency of removal of B19 DNA during manufacture. Br J Haematol 1996;93:714-719.

4 Gibb AP, Martin KM, Davidson GA, Walker B, Murphy WG: Modelling the growth of Yersinia enterocolitica in donated blood. Transfusion 1994;34:304-310.
5 Department of Health: Why Mothers Die: Report on Confidential Enquiries into Maternal Deaths 1994/96. London: Her Majesty's Stationery Office, 1998.

6 May R: Simple mathematical models with very complicated dynamics. Nature 1976;261:459467.

7 Eastlund T: Monetary blood donation incentives and the risk of transfusion-transmitted infection. Transfusion 1998;38:874-882.

8 Seifried E, Hitzler W: Status of NAT screening for HCV, HIV and HBV: Experience in Germany. Infus Ther Transfusion Medicine 2001; 28:231 (abstract). 